\title{
Socio-climatic hotspots in Brazil: how do changes driven by the new set of IPCC climatic projections affect their relevance for policy?
}

\author{
João Paulo Darela Filho ${ }^{1}$ (D) David M. Lapola ${ }^{1}$. \\ Roger R. Torres ${ }^{2} \cdot$ Maria Carmen Lemos ${ }^{3}$
}

Received: 12 May 2015 / Accepted: 21 February 2016 / Published online: 8 March 2016

(C) Springer Science+Business Media Dordrecht 2016

\begin{abstract}
This paper updates the SCVI (Socio-Climatic Vulnerability Index) maps developed by Torres et al. (2012) for Brazil, by using the new Coupled Model Intercomparison Project Phase 5 (CMIP5) projections and more recent 2010 social indicators data. The updated maps differ significantly from their earlier versions in two main ways. First, they show that heavily populated metropolitan areas - namely Belo Horizonte, Brasília, Salvador, Manaus, Rio de Janeiro and São Paulo - and a large swath of land across the states of São Paulo, Minas Gerais and Bahia now have the highest SCVI values, that is, their populations are the most vulnerable to climate change in the country. Second, SCVI values for Northeast Brazil are considerably lower compared to the previous index version. An analysis of the causes of such difference reveals that changes in climate projections between CMIP3 and CMIP5 are responsible for most of the change between the different SCVI values and spatial distribution, while changes in social indicators have less influence, despite recent countrywide improvements in social indicators as a result of aggressive anti-poverty programs. These results raise the hypothesis that social reform alone may not be enough to decrease people's vulnerability to future climatic changes. Whereas the coarse spatial resolution and relatively simplistic formulation of the SCVI may limit how useful these maps are at informing decision-making at the local level, they can
\end{abstract}

Electronic supplementary material The online version of this article (doi:10.1007/s10584-016-1635-z) contains supplementary material, which is available to authorized users.

João Paulo Darela Filho

jpdarela@rc.unesp.br

1 Earth System Science Laboratory, Department of Ecology, São Paulo State University - UNESP, Rio Claro, SP 13506-900, Brazil

2 Natural Resources Institute, Federal University of Itajubá (IRN/UNIFEI), Itajubá, MG 37500-903, Brazil

3 School of Natural Resources and Environment, University of Michigan, Ann Arbor, MI, USA 
provide a valuable input for large-scale policies on climate change adaptation such as those of the Brazilian National Policy on Climate Change Adaptation.

\section{Introduction}

Current climatic projections indicate that considerable changes may occur in the climate of Brazil during the twenty-first century (Torres and Marengo 2014; Magrin et al. 2014). Considering that in Brazil the production of food, commodities and energy is highly dependent on climate and that a considerable part of the population is in a socially vulnerable situation (i.e. with overall low human development levels and/or living in risky areas), it is expected that climate change will likely have strong negative social impacts (Magrin et al. 2014). Examples of climate-driven high social and economic costs are evident in the current severe four-year drought that has negatively affected water availability in large cities in Southeast Brazil (Coutinho et al. 2015) and caused relentless suffering in Northeast Brazil (Lindoso et al. 2014).

While climate change mitigation has been on the agenda of the Brazilian government for several years (IPEA 2011), effective long term adaptation planning has lagged. In this context, the development of decision support efforts to map priority areas for action or for the development of long-term adaptation policies is of crucial importance in a country of continental dimensions such as Brazil. This is particularly relevant in the context of rapid social change as a result of anti-poverty programs implemented in the country in the past 15 years. These programs may influence the level of vulnerability of households and communities to climate change, particularly in regions of high climate exposure such as large metropolitan areas in the Southeast and parts of the Brazilian Amazon and semi-arid Northeast Brazil (Eakin et al. 2014; Di Giulio and Vasconcellos 2014).

On the one hand vulnerability indices and indicators may be helpful because they bring together and summarize a large array of information that compares relative dimensions of risk across large spatial areas. They may also help public officials understand the relative importance of different social policies in modulating climate-driven risk (Eakin et al. 2014). By informing how effective policies are at decreasing socio-climatic vulnerability over time, such indicators can facilitate incremental refinements of strategies that seek to improve adaptive capacity and resilience in highly vulnerable areas (Ranger 2013; Walker et al. 2013). On the other hand, the development of such indicators is fraught with challenges that limit their usability. Frequently identified problems with indicators include lack of robust metrics, cross scale aggregation and standardization; lack of data availability and access; and compounded uncertainty (Eakin and Luers 2006; Vincent 2007; Barnett et al. 2008; Hinkel 2011; Preston et al. 2011; Ranger and Surminski 2013; Ranger 2013; Sherbinin 2014). The limitations of indicators are particularly acute where data and resources are not adequate to develop the best measurements recommended by scientists, especially in less developed regions (Ranger and Surminski 2013).

Yet, the proliferation of vulnerability indicators and hotspots mapping around the world (Barnett et al. 2008; Sherbinin 2014) suggests that in spite of these recognized challenges, they may hold promise in supporting decision-making. In this article, we argue that it is precisely in their ability to synthetize complex information in an accessible format that the value of indicators is to be found, if not as precise tools for specific decision-making such as identifying 
vulnerable groups or monitoring adaptation measures (for extensive reviews of the indicators literature see Hinkel 2011 and Sherbinin 2014), then perhaps as support for broader scale decision-making such as priority mapping and long term risk communication (Sherbinin 2014) and understanding relative drivers/importance of vulnerabilities and capacities (Eakin et al. 2014). For example, by providing information across time and space about changing vulnerabilities, such maps can support decision-making regarding where investment in human development at the household level (i.e. education, health and income) can make a difference relative to other areas where specific large scale risk management interventions at the institutional level (e.g. public works/infrastructure, planned migration) may be necessary to decrease vulnerability in the long run (Eakin et al. 2014).

In this study, we seek to contribute to this discussion by updating the SCVI (Socio-Climatic Vulnerability Index) map developed by Torres et al. (2012) for Brazil, exploring the differences between the SCVI map published by Torres et al. (hereafter, SCVI-1) and the updated $S C V I$ map (hereafter SCVI-2), and discussing potential policy implications of these differences. We use climatic data from the Coupled Model Intercomparison Project Phase 5 (CMIP5) and explore a number of more recent social indicators (2010) to elaborate and analyze the new SCVI map (SCVI-2). In the next sections, we describe the creation of the SCVI maps and discuss their potential implications for decision-making. In section 2 , we describe the method and data used for developing the new SCVI. In section 3, we carry out a sensitivity analysis of our indices across the two SCVI maps (SCVI-1 and SCVI-2) and compare them. We conclude with a brief discussion of our results and implications for policy and decision-making.

\section{Creating a new suite of $S C V I$ maps for Brazil}

To understand overall vulnerability at the country level we follow IPCC's general definition of vulnerability that combines exposure, sensitivity and adaptive capacity (IPCC 2014). To account for exposure we use the Regional Climate Change Index (RCCI) developed by Giorgi (2006) and applied to South America by Torres and Marengo (2014). The RCCI is a qualitative index that summarizes a large amount of data from climate projections in a clear and reliable way and on a relative basis. It highlights regions where climate change (changes in mean and inter-annual variability of surface temperature and precipitation) will be more pronounced in a given territorial domain. To account for sensitivity and adaptive capacity, we use socio-economic indicators often found in the literature (Sherbinin 2014) and based on the 2010 Brazilian census, namely population density and human development index.

In 2012, the SCVI was built by coupling the RCCI (using climate projections from CMIP3 Coupled Model Inter-comparison Project Phase 3) with a high-resolution map of population density (Goldewijk et al. 2010) and Brazil's human development index at the municipality level (MHDI) based on the 2000 census (Torres et al. 2012). The SCVI-1 shows that although the Center-West and North regions of Brazil presented the most severe climate change projections, Northeast Brazil (due to low MHDI values) and major Brazilian cities (due to high population density) showed the highest levels of socioeconomic vulnerability. Since then, both a new set of global climate projections from CMIP5 - which were used in the IPCC Fifth Assessment Report (AR5) - and more recent data on MHDI and Brazil's population density have become available. 


\subsection{SCVI}

The SCVI is an index that aggregates information on the intensity of climate change with social factors that may influence the vulnerability of the population in a given region (Torres et al. 2012) and is defined as:

$$
S C V I_{j}=C I_{j} * \sqrt[n]{\prod_{i=1}^{n} F_{i_{j}}}
$$

where $C I_{j}$ represents any climate change index available for the study area (in our case, the $R C C I$ described in the next section), whereas the right hand term represents the geometric mean of $i$ normalized social indicators $\left(F_{i}\right)$ representing both sensitivity (population density) and adaptive capacity (MHDI). The $S C V I$ is calculated for each grid point $j$ of the studied domain. As in Torres et al. (2012), the social indicators used in this update are population density (Goldewijk et al. 2010) and the MHDI (PNUD et al. 2013). While in Torres et al. (2012), the social indicators were based on the 2000 data, this update uses 2010 census data.

The methodological change that was carried out in the calculation of MHDI from census data between the years 2000 and 2010 (see PNUD et al. 2013) would restrict a direct comparison between the two SCVI versions (see section 3 below). Therefore, we recalculated the SCVI-1 with climate data from CMIP3, the population density for the year 2000 and the MHDI-2000 calculated by the same method used for the MHDI-2010. Population density has a spatial resolution of five arc-minutes, while MHDI is presented at the municipality level. The formulation of SCVI implies that the socio-climatic vulnerability will be more pronounced in locations where the population density is high and the MHDI is low, in agreement with Torres et al. (2012). As such, in the SCVI population density represents both the geographic location and people's sensitivity in a given location, whereas the inverse of MHDI represents a lack of adaptive capacity in a population. We acknowledge the limitations of using HDI as a measure of exposure at the spatial resolution employed here, but it is apparently the most consistent and coherent indicator available at the municipality scale covering entire Brazil.

Both the RCCI and SCVI were calculated for a horizontal regular grid of $1^{\circ} \times 1^{\circ}$ latitude/ longitude. The preparation of data and calculation of SCVI-2 followed the same procedures described in the study by Torres et al. (2012). The definitions of vulnerability and adaptation used in this study are the same as those used by the IPCC (2007/2014), meaning that the resulting SCVI map denotes areas where people are more or less exposed and/or are more sensitive/susceptible to climate change and have difficulty coping or adapting to climate change. Like the RCCI, the $S C V I$ is a qualitative index, meaning that the information is not contained in the absolute value of the index but instead in the comparison of their values between regions in the considered study area. Thus, low values of these indices do not indicate an absence of climate change and socio-climatic vulnerability, rather, they represent lower values on a relative basis.

\subsection{RCCI}

The Regional Climate Change Index is based on several variables representing climate change: 1) change in temperature in a given specific region relative to the change in global mean temperature (or regional warming amplification factor - $R W A F$, dimensionless); 2) change in average rainfall ( $\Delta \mathrm{P}, \%$ of current climate value); and 3$)$ changes in the interannual variability 
of temperature ( $\Delta \sigma_{T}, \%$ of current climate value) and precipitation $\left(\Delta \sigma_{P} \%\right.$ of the value of the present climate). All changes addressed in this study relate to projections for the period of 2071-2100 relative to 1961-1990. All these variables were calculated for austral summer (DJF) and winter (JJA), as done by Xu et al. (2009) (for further details see Giorgi (2006); Torres et al. (2012), and Torres and Marengo (2014)).

Thus, the $R C C I$ is ultimately defined for each location or grid point $j$ as:

$$
\begin{aligned}
R C C I_{j}= & {\left[n\left(\left|\Delta P_{j}\right|\right)+n\left(\left|\Delta \sigma_{p_{j}}\right|\right)+n\left(R W A F_{j}\right)+n\left(\left|\Delta \sigma_{T_{j}}\right|\right)\right]_{D J F} } \\
& +\left[n\left(\left|\Delta P_{j}\right|\right)+n\left(\left|\Delta \sigma_{p_{j}}\right|\right)+n\left(R W A F_{j}\right)+n\left(\left|\Delta \sigma_{T_{j}}\right|\right)\right]_{J J A}
\end{aligned}
$$

where $n$ is an empirical factor that assumes the value $0,1,2$, or 4 , depending on the magnitude of the change involved (Table 1). For example, assuming a hypothetical location (or grid point) $j$ that presents for austral summer $\Delta \mathrm{P}=2 \%, \Delta \sigma_{P}=18 \%, R W A F=1.2$, and $\Delta \sigma_{T}=16 \%$; and for austral winter $\Delta \mathrm{P}=14 \%, \Delta \sigma_{P}=8 \%, R W A F=1.4$, and $\Delta \sigma_{T}=-20 \%$. Therefore, consulting Table 1, the RCCI assumes the dimensionless value:

$$
\mathrm{RCCI}=[0+2+1+4]_{D J F}+[2+1+2+4]_{J J A}=16 .
$$

The same procedure is carried out for all grid points in the domain of the study, and the $R C C I$ values are compared among locations to identify, on a relative basis, the regions in which climate change may be more prominent.

The variables $\Delta P, \Delta \sigma_{P}$ e $\Delta \sigma_{T}$ can assume positive and negative values, so the absolute values are included in the RCCI calculation. This is due to the fact that both of the signals may cause impacts in different ways; for example, a region may be vulnerable to floods due to increased precipitation or to droughts due to lower precipitation.

The interannual standard deviation of temperature is used as a measure of $\sigma_{T}$, and the coefficient of variation is used as a measure of $\sigma_{P}$. Both $\sigma_{T}$ and $\sigma_{P}$ are calculated for the selected thirty-year periods following the detrending of the data, in order to obtain unbiased variability estimates (Giorgi 2006). The coefficient of variation is used as a measure of interannual precipitation variability because it removes the dependency of the standard deviation on the mean for zero-bounded variables such as rainfall (Räisänen 2002; Giorgi 2006).

The $R C C I$ version used in this update comprises simulated (1961-1990) and projected (2071-2100) monthly means of near-surface air temperature and precipitation from a set of 24 general circulation models (GCM) of CMIP5 (See IPCC 2013; Torres and Marengo 2014). The climate projections of CMIP5 that were used in IPCC-AR5 (IPCC 2013) were delineated using a new generation of climate forcing scenarios, called representative concentration pathways (RCPs) (Moss et al. 2010).

Table 1 Values of the factors $n$ used in the definition of $R C C I$

\begin{tabular}{lllll}
\hline$n$ & $|\Delta P|$ & $\left|\Delta \sigma_{P}\right|$ & $R W A F$ & $\left|\Delta \sigma_{T}\right|$ \\
\hline 0 & $<5 \%$ & $<5 \%$ & $<1.1$ & $<5 \%$ \\
1 & $5-10 \%$ & $5-10 \%$ & $1.1-1.3$ & $5-10 \%$ \\
2 & $10-15 \%$ & $10-20 \%$ & $1.3-1.5$ & $10-15 \%$ \\
4 & $>15 \%$ & $>20 \%$ & $>1.5$ & $>15 \%$ \\
\hline
\end{tabular}


The spatial resolutions of the CMIP3 models used in the first version of the $R C C I$ (hereafter $R C C I$-CMIP3) ranged from approximately $1^{\circ}$ to $5^{\circ}$ latitude/longitude, while the CMIP5 models used by Torres and Marengo (2014) to update $R C C I$ (hereafter RCCI-CMIP5) have a slightly more refined spatial resolution (between $1^{\circ}$ and $3^{\circ}$ latitude/longitude). Relevant developments in the GCMs used in CMIP5 were: a) improvements in the atmosphere-ocean coupling, b) inclusion of the carbon cycle, c) the use of more comprehensive radiative forcing due, among other processes, to a more accurate modeling of the indirect effects of aerosols, and d) the use of time series of volcanic and solar forcing in most models (Taylor et al. 2012; Knutti and Sedlácek 2013 Sillmann et al. 2013).

For the $R C C I$ calculation, all climate variables and statistics were computed as follows: 1) the change was calculated for each model simulation; 2) when available, different runs using the same model were averaged; 3 ) the results were interpolated to a $1^{\circ}$ latitude/longitude spatial resolution; 4) the ensemble average over the different available models was obtained; and 5) the different forcing scenarios were averaged. Steps 4 and 5 were ignored when a sensitivity test was conducted to assess variance in SCVI related to the different climate models and forcing scenarios.

As shown in Torres and Marengo (2014), the highest RCCI values in Brazil in the updated version are concentrated in southern Amazon and northern Mato Grosso regions, and the western portion of the state of Minas Gerais. Analyzing the RCCI-CMIP5 maps, a noticeable difference appears in the Brazilian states of Maranhão, Piauí, the northwest region of Pará, and in the states of Acre, Amazonas, and Roraima, when compared with the RCCI-CMIP3 results (Fig. 1). However, outside these regions, the $R C C I$ pattern is fairly comparable between the two multi-model sets, which demonstrates a relatively good agreement between the CMIP3 and CMIP5 results.
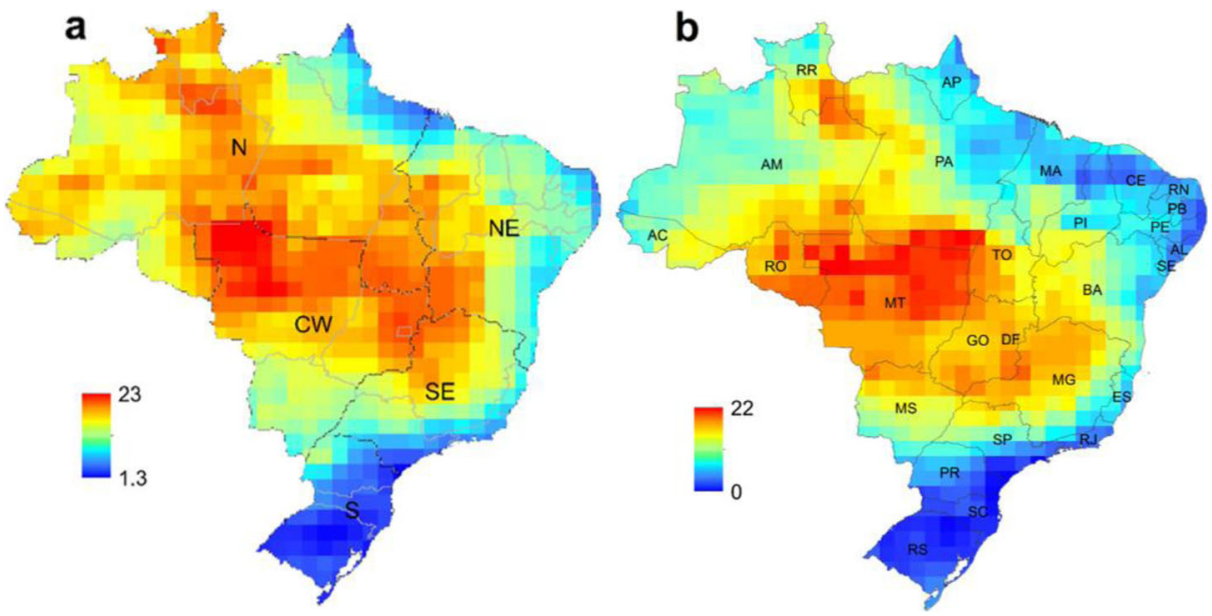

Fig. 1 a Regional climate change index using CMIP3 data from Torres et al. (2012). b Regional climate change index using CMIP5 data from Torres and Marengo (2014). Panel (a) also shows Brazil macro-regions: N: North, CW: Center-West, NE: Northeast, SE: Southeast, S: South. Panel (b) also shows Brazilian States: AC: Acre, AL: Alagoas, AM: Amazonas, AP: Amapá, BA: Bahia, CE: Ceará, DF: Distrito Federal, ES: Espírito Santo, GO: Goiás, MA: Maranhão, MG: Minas Gerais, MS: Mato Grosso do Sul, MT: Mato Grosso, PA: Pará, PB: Paraíba, PE: Pernambuco, PI: Piauí, PR: Paraná, RJ: Rio de Janeiro, RN: Rio Grande do Norte, RO: Rondônia, RR: Roraima, RS: Rio Grande do Sul, SC: Santa Catarina, SE: Sergipe, SP: São Paulo, TO: Tocantins 


\section{Comparative analysis and sensitivity test}

To assess the causes of differences between SCVI-1 and SCVI-2, a cell-to-cell comparison was performed between the two index versions through the following steps:

- A new map of SCVI was calculated using social indicators from SCVI-2 (population density and MHDI from year 2010) and climate data from SCVI-1 (RCCI-CMIP-3). The resulting map is referred to as comparison map 1 (CM1)

- The standard deviation and the difference (in percentage) between:

a. CM1, and SCVI-1 (in which the underlying difference between the maps was solely the socio-economic indicators)

b. SCVI-2 and SCVI-1 (in which underlying difference between the maps were both climatic data and socio-economic indicators).

Additionally, we conducted a test of robustness of our proxy indicators for (1) social adaptive capacity and (2) of the variability associated with the $>300$ climate projections used to calculate this updated version of SCVI. For (1), we explored specifically the robustness of using MHDI as an indicator of adaptive capacity to climate change by identifying a set of other 20 variables that scholars have theorized to be related to vulnerability and which were available for Brazil. These included the GINI index, access to adequate water supply, access to electricity, etc. (see complete list of variables in Supplementary Material document). Next we replaced MHDI with each of these variables and calculated 20 different versions of SCVI. The results of this test is shown in SM-Figure 1 and are also briefly discussed in the next session. For (2), the climate projections variability analysis, we calculated the $R C C I$ for each and every climate model and forcing scenario and with the subsequent calculation of SCVI (with fixed 2010 population density and MHDI) and separately extracted the standard deviation from this set of SCVI maps. The results of this climate projection variability analysis are shown in Fig. 2b.

\section{Results and discussion}

Figure 2 shows that the main differences between the original and updated versions of SCVI are twofold. First there is a pronounced decrease in the $S C V I$ for the Northeast Brazil region. Second, there is an increase observed for the swath of land running from the São Paulo metropolitan area through the state of Minas Gerais and up to Salvador (capital of the state of Bahia). The levels of vulnerability in this strip of land are the highest in Brazil according to the updated version of the index. In general, in this update, all Brazilian state capitals showed high SCVI values, except Porto Alegre (in the state of Rio Grande do Sul), Florianópolis (in the state of Santa Catarina), Boa Vista (in the state of Roraima), and Palmas (in the state of Tocantins) (Table 2).

As in the SCVI-1, these high values for the metropolitan areas are a result of the high population density found in these locations. While several metropolitan regions have higher MHDI values when compared with other regions of Brazil, their high population densities encompass huge social inequalities as shown by the example of the city of São Paulo: whereas some neighborhoods have HDI values typical of Scandinavian countries (e.g. Moema $=0.955$; 

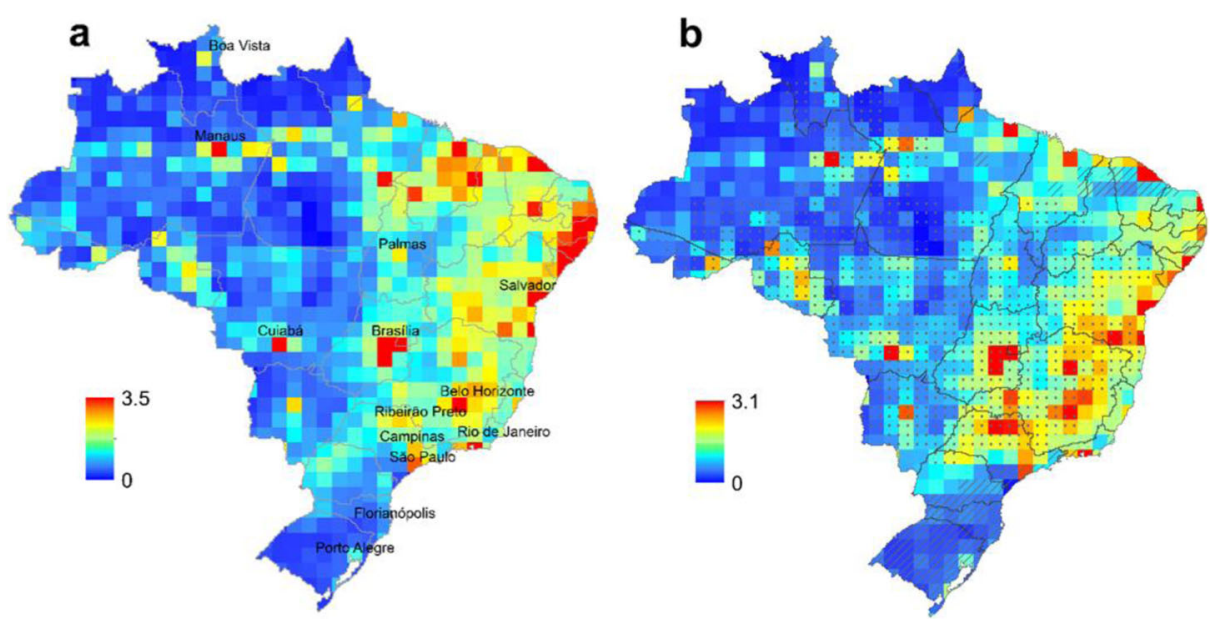

Fig. 2 a SCVI calculated with social data for the year 2000 and climatic data from CMIP3, and (b) updated SCVI calculated with social indicators for the year 2010 and climatic data from CMIP5. In panel (b) hatching indicates regions where climate projection-related uncertainty is high, given that mean SCVI values are small compared to the variability of climate projections (less than one standard deviation); stippling indicate regions where climate projection-related uncertainty is low given that SCVI mean is large compared with variability of climate projections (higher than two standard deviations). Uncertainty related to socio-economic indicators of vulnerability is relatively low in the entire map given that mean SCVI values are large compared with variability of socio-economic indicators (higher than two standard deviations; see Supplementary Material for details) and, as such, no hatching or stippling related to social indicators were applied to panel (b)

Norway $=0.955)$, other parts of the city have HDI similar to many of the poorest countries in Latin America (e.g. Parelheiros $=0.670$; Bolivia =0.667) (PNUD et al. 2013; UNDP 2014). These social inequalities, inherent to many Brazilian metropolitan areas, make them particularly vulnerable to climate change problems such as floods and outbreaks of infectious diseases (Patz et al. 2005).

From the perspective of the five Brazilian macro-geographical regions, Southeast Brazil has the highest average $S C V I$ value, primarily due to moderate values of $R C C I$ and high population density. Table 3 illustrates this perspective. The high values in the SCVI-2 found in the axis of São Paulo-Campinas-Ribeirão Preto-São José do Rio Preto in the state of São Paulo is particularly worrisome since this is a region with a population of more than 30 million people (in 2010) in the process of fast economic expansion. The severe drought currently affecting a large portion of the state of São Paulo and particularly the metropolitan region of São Paulo city is, however, a glaring example of how economic prosperity does not necessarily mean low vulnerability to climate change and how it may actually mask hidden tradeoffs between

Table 2 SCVI values for major metropolitan regions in Brazil. This table illustrates changes in the vulnerability ranking of these metropolitan regions given that a direct comparison between the two SCVI versions must be approached with care due to the relative nature of SCVI values

\begin{tabular}{lll}
\hline Metropolitan regions & SCVI-1 & SCVI-2 \\
\hline Belo Horizonte & 3.0 & 3.1 \\
Brasília & 3.0 & 2.4 \\
Salvador & 3.0 & 2.3 \\
Manaus & 3.5 & 2.1 \\
Rio de Janeiro & 2.4 & 1.4 \\
São Paulo & 1.7 & 1.2 \\
\hline
\end{tabular}


Table 3 Mean values of updated SCVI (dimensionless); RCCI CMIP5 (dimensionless); municipal human development index (MHDI-2010, dimensionless); and estimated demographics (average population density in inhabitants $/ \mathrm{km}^{2}$ per grid cell in 2010) for each macro-region of Brazil used as input in this update. Figures in brackets are those published by Torres et al. (2012) with the exception of the MHDI row. In this row, the values in brackets represent the MHDI 2000 calculated by PNUD et al. (2013). Geographical location of Brazilian macroregions can be seen in Fig. 1a

\begin{tabular}{llllll}
\hline & North & Northeast & Central West & Southeast & South \\
\hline SCVI & $0.24(0.32)$ & $0.60(0.94)$ & $0.39(0.41)$ & $0.76(0.77)$ & $0.23(0.28)$ \\
RCCI & $11.83(15.99)$ & $8.59(13.01)$ & $16.06(17.71)$ & $11.29(12.86)$ & $3.38(4.81)$ \\
MHDI & $0.608(0.443)$ & $0.590(0.422)$ & $0.690(0.551)$ & $0.698(0.589)$ & $0714(0.603)$ \\
Demography & $4(3.82)$ & $37.21(33,48)$ & $8.04(7.52)$ & $89.92(80.45)$ & $50.20(45.18)$ \\
\hline
\end{tabular}

development and risk management (Eakin et al. 2014; Agrawal and Lemos 2015). Similarly the region that extends from the north of Minas Gerais to the metropolitan area of Salvador, pointed here as having high socio-climatic vulnerability, hosts approximately 10 million people and is known for its high social inequality and sensitivity to drought (Ribeiro and Galizoni 2003).

The robustness analysis on the use of MHDI as an indicator of vulnerability/adaptive capacity (described in section 3) revealed that there is a relatively low uncertainty related to social indicators in Brazil (see Fig. 2 and Supplementary Material). This analysis also provides first-order indications of the type of actions necessary to reduce people's vulnerability to climate change, such as providing people with an adequate water supply (SM-Figure 1.o).

Although MHDI values have significantly increased throughout Brazil between 2000 and 2010 (PNUD et al. 2013), the comparison of SCVI-1 and SCVI-2 also described in section 3 shows that areas of no consensus between the two index versions, particularly in Northeast Brazil, arose mainly from changes between the two $R C C I$ versions, that is, due to changes in the set of climatic projections occurred between CMIP3 and CMIP5 (Fig. 3). Despite the fact that climate change indices such as $R C C I$ and mixed indices, such as SCVI, are potentially useful in communicating climate change, social vulnerability and risk in a more concise and clear way, the comparison between these two sets of indexes demonstrates they are very susceptible to updates in climatic projections derived from constant (and necessary) revisions/ changes/updates in climate models.

As discussed by Torres and Marengo (2014), because several studies have identified a slight improvement in the climatological representation of South America in CMIP5 (Blázquez and Nunes 2012; Jones and Carvalho 2013), the relative consistency between the two different generations of GCMs and the better representation in CMIP5 of observed climate conditions increases the reliability of the presented projections. However, periodic changes in instruments conceived to enhance science-policy communication - as is the case of SCVI-can undermine the confidence of decision-makers considering different policy options. In this case, even if several of these changes are limited to a small region or a few pixels, they may represent millions of people and substantial amounts of resources at stake.

Furthermore, the considerable change in MHDI between 2000 and 2010 - mainly in Northeast Brazil (PNUD et al. 2013) suggests that higher levels of human development at the local level were not enough to change the $S C V I$ values significantly (Figs. 3a and c). While the discrepancies between SCVI-1 and SCVI-2 may be due to the differences in climate projections, they call attention to the possibility that recent social gains from anti-poverty 


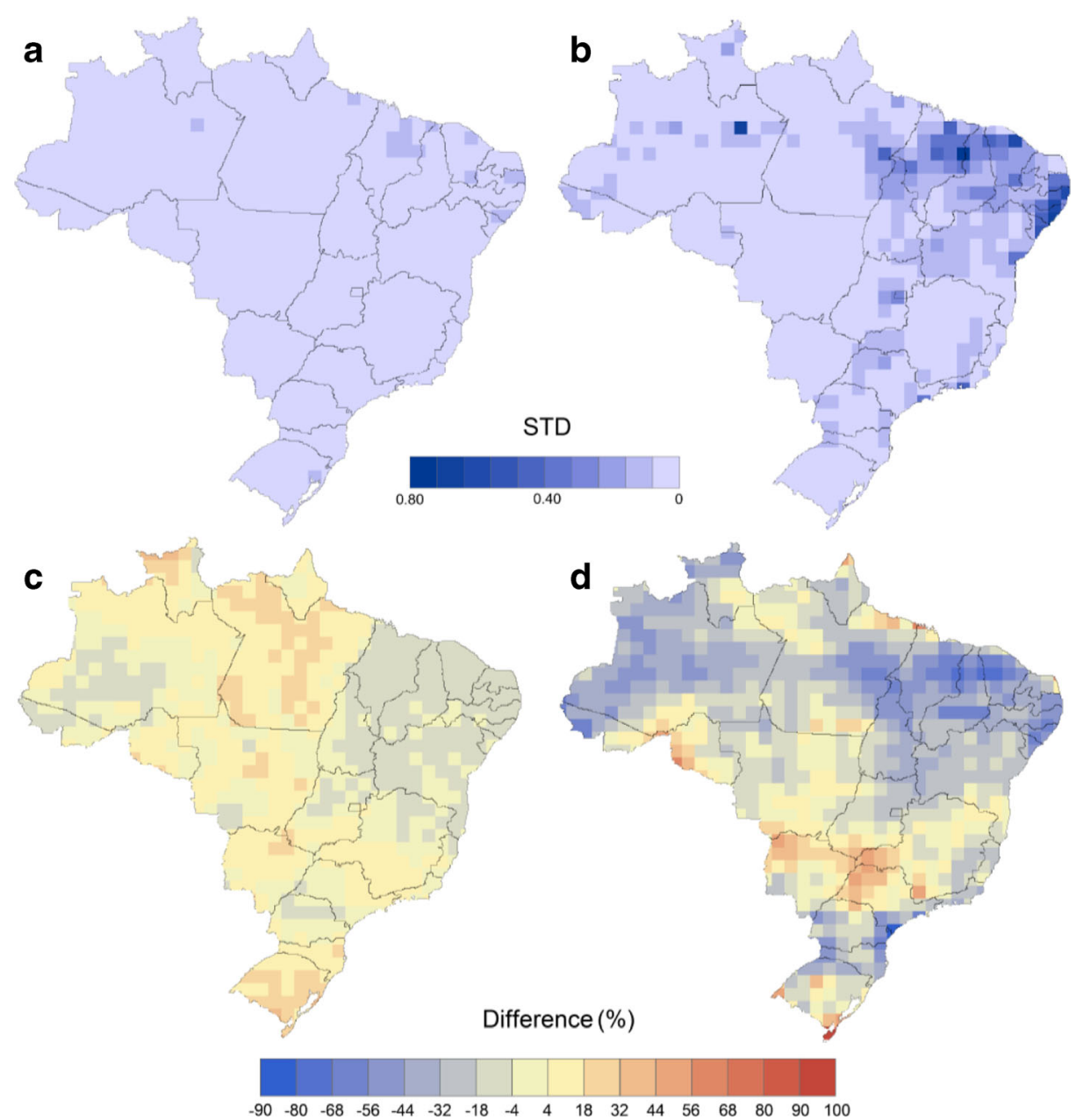

Fig. 3 a Standard deviation between SCVI-1 and CM1 (CM1 is an SCVI variant calculated from the intersection of social data for the year 2010 and CMIP3 climate data; see section 3 for details). This map highlights the influence of social indicators on the differences between SCVI-1 (Torres et al. 2012) and SCVI-2 (presented in this study). b Standard deviation between SCVI-1 and SCVI-2, the comparison of this map with (a) shows the influence of the new CMIP5 climate data on the differences between the SCVI versions. c Difference between CM1 and SCVI-1 (in that order); (d) Difference between SCVI-2 and SCVI-1 (in that order).

programs may be offset by climatic change (World Bank 2010; Eakin et al. 2014). Here the limitations of this kind of mapping in exposing the complex relationship between poverty, development interventions and climate vulnerability become more salient. Yet, they can generate a number of valuable hypotheses for scholars of vulnerability and decision-makers that need to be explored to inform future policy. This is especially true in terms of the different kinds of capacities (e.g. human development vs. risk management) and their relative importance in decreasing the overall impact of climate events (Eakin et al. 2014). For example, since the late 1990s the Brazilian government has embarked on an ambitious anti-poverty program (called Bolsa Família) that transfers cash to all families under a certain level of income provided they keep their kids in school and vaccinate them as infants. While gains in terms 
of MHDI have been significant in all aspects of human development across all Brazilian states (income, life expectancy and education) (PNUD et al. 2013), in the state of Ceará, one of the poorest in the Brazilian Northeast, the ability of poor households in the program to prepare and respond to drought (measured by food security) has been limited mostly because their lack of access to risk management assets such as irrigation and access to water. This suggests that the new policy approaches that focus on household human development while phasing out emergency interventions (such as distribution of food baskets) may be necessary but insufficient to respond to severe drought events (Eakin et al. 2014). While our hotspots map shows that Northeast Brazil is among the most vulnerable regions in Brazil despite an increase in MHDI (see Table 3), it does not show the details of the relationship between poverty, social interventions and vulnerability described in the example above well enough to inform specific policy at the household level.

However, our results - especially in terms of the relative impact of climate and social variables in explaining vulnerability - raise the hypothesis that social reform alone may not be enough to decrease people's overall vulnerability to forthcoming climatic changes. In this sense hotspot maps can expose the potential inadequacy of current policies and more effectively communicate changing trends - not only for Northeast Brazil but also true for wealthierthough-unequal regions such as São Paulo. Given that this study presents and analyzes a situation in which the climate of 2050 affects a population with a level of exposure, sensitivity and adaptive capacity as of 2010, one should expect that profound and somewhat unpredictable changes in social indicators may occur between now and 2050.

Nevertheless, exercises such as the one described in this paper, which expose not only the current average vulnerability of human populations but also the level of uncertainty associated with current indicators and climate models, enable scholars to reinforce the need for policy makers to design adaptive policy that place risk front and center when planning for development in the next few years (Agrawal and Lemos 2015).

\section{Concluding remarks}

The use of the latest generation of climate projections and social indicators significantly changes the SCVI for Brazil with the most vulnerable populations located in several cities and particularly in the rural areas of the states of São Paulo, Minas Gerais, and Bahia (rather than most of the Northeast Brazil region, as seen in the previous $S C V I$ version). The observed changes between the two versions of the index are derived primarily from the new climate data from CMIP5 used in IPCC-AR5.

Our study suggests that climate change indicators/indexes have to be considered cautiously by decision-makers seeking to design and implement policy in response to climate change impacts. On the one hand, it indicates that this kind of exercise can be useful for understanding the relative importance of different drivers of vulnerability and the impact that social welfare policies can have in reducing vulnerability. On the other hand, it shows how the improvement of data and models is necessary but can become a confounding issue in terms of science usability. Above all, both scientists and decision-makers must consider that social vulnerability is an extremely complex concept, which is defined primarily at the local level; highly aggregated analysis such as the one depicted here needs to be understood in this context. In this sense, the maps produced in this study can then be taken as a first-order assessment of the problem of climate change adaptation at the national level, potentially providing valuable input 
for the forthcoming Brazilian National Policy on Climate Change Adaptation, under development by the federal government - especially regarding actions to promote adaptation in the most vulnerable human populations and communities. However, a careful explanation of its limitations and uncertainties need and should be a part of any conversation with policy makers seeking to decrease vulnerability at the national level.

Acknowledgments This study was supported by São Paulo Research Foundation - FAPESP (grant $n^{\circ}$ 2013/09742-0), by the Minas Gerais State Research Foundation - FAPEMIG (APQ-01088-14) and the U.S. National Science Foundation (NSF grant $n^{\circ}$ SES-1061966). We are grateful to T. Siqueira for his helpful suggestions on this study.

\section{References}

Agrawal A, Lemos MC (2015) Adaptive development. Nat Clim Chang 5:185-187. doi:10.1038/nclimate2501 Barnett J, Lambert S, Fry I (2008) The hazards of indicators: insights from the environmental vulnerability index. Ann Assoc Am Geogr 98:102-119. doi:10.1080/00045600701734315

Blázquez J, Nunes M (2012) Performance of a high resolution global model over Southern South America. Int J Climatol. doi:10.1002/joc.3478

Coutinho RM, Kraenkel RA, Prado PI (2015) Catastrophic regime shift in Water reservoirs and São Paulo Water Supply crisis. PLoS One 10:e0138278. doi:10.1371/journal.pone.0138278

Di Giulio GM, Vasconcellos MP (2014) Contribuições das Ciências humanas para o debate sobre mudanças ambientais: um olhar sobre São Paulo. Estudos Avançados [Online] 28(82):41-63. doi:10.1590/S010340142014000300004 Accessed 19 Oct 2015

Eakin H, Luers AL (2006) Assessing the vulnerability of Social-Environmental Systems. Annu Rev Environ Resour 31:365-394. doi:10.1146/annurev.energy.30.050504.144352

Eakin H, Lemos MC, Nelson DR (2014) Differentiating capacities as a means to sustainable climate change adaptation. Glob Environ Chang 27:1-8. doi:10.1016/j.gloenvcha.2014.04.013

Giorgi F (2006) Climate change hot-spots. Geophys Res Lett 33:1-4. doi:10.1029/2006GL025734

Goldewijk K, Beusen A, Janssen P (2010) Long-term dynamic modeling of global population and built-up area in a spatially explicit way: HYDE 3.1. The Holocene 20:565-573. doi:10.1177/0959683609356587

Hinkel J (2011) "indicators of vulnerability and adaptive capacity": towards a clarification of the science-policy interface. Glob Environ Chang 21:198-208. doi:10.1016/j.gloenvcha.2010.08.002

IPCC (2007) Summary for policymakers. In: Solomon S, Qin D, Mamming M, Chen Z, Marquis M, Averyt KB, Tignor M, Miller HL (eds) Climate change 2007: the physical science basis. Contribution of Working Group I to the Fourth Assessment Report of the Intergovernmental Panel on Climate Change. Cambridge University Press, Cambridge

IPCC (2013) Climate change 2013: the physical science basis. contribution of Working Group I to the fifth assessment report of the intergovernmental panel on climate change. Cambridge University Press, Cambridge

IPCC (2014) Climate change 2014: impacts, adaptation, and vulnerability. Part A: global and sectoral aspects. Contribution of working group II to the fifth assessment report of the intergovernmental panel on climate change. Cambridge University Press, Cambridge

IPEA (Instituto de Pesquisa Econômica Aplicada) (2011). Climate change in Brazil: economic, social and regulatory aspects http:/www.ipea.gov.br/agencia/images/stories/PDFs/livros/livros/livro_climatechange.pdf. Accessed 19 Oct 2015

Jones C, Carvalho LMV (2013) Climate change in the South American monsoon system: present climate and CMIP5 projections. J Clim. doi:10.1175/JCLI-D-12-00412.1

Knutti R, Sedlácek J (2013) Robustness and uncertainties in the new CMIP5 climate model projections. Nat Clim Chang. doi:10.1038/nclimate1716

Lindoso DP, Rocha JD, Debortoli N, et al. (2014) Integrated assessment of smallholder farming's vulnerability to drought in the Brazilian semi-arid: a case study in Ceará. Clim Chang 127:93-105. doi:10.1007/ s10584-014-1116-1

Magrin GO, Marengo JA, Boulanger J-P, Buckeridge, MS, Castellanos E, Poveda G, Scarano, FR, Vicuña S (2014) Central and South America. In: Climate Change 2014: Impacts, Adaptation, and Vulnerability. Part B: Regional Aspects. Contribution of Working Group II to the Fifth Assessment Report of the Intergovernmental Panel on Climate Change. Cambridge University Press, Cambridge 
Moss RH, Edmonds JA, Hibbard KA, et al. (2010) The next generation of scenarios for climate change research and assessment. Nature 463:747-756. doi:10.1038/nature08823

Patz JA, Campbell-Lendrum D, Holloway T, Foley JA (2005) Impact of regional climate change on human health. Nature 438:310-317. doi:10.1038/nature04188

PNUD (Programa das Nações Unidas Para o Desenvolvimento), IPEA (Instituto de Pesquisa Econômica Aplicada), Fundação João Pinheiro (2013) Atlas do Desenvolvimento Humano no Brasil 2013. http://www.atlasbrasil.org. br/2013/. Accessed 19 Oct 2013

Preston BL, Yuen EJ, Westaway RM (2011) Putting vulnerability to climate change on the map: A review of approaches, benefits, and risks. Sustain Sci 6:177-202. doi:10.1007/s11625-011-0129-1

Räisänen J (2002) CO2-induced changes in interannual temperature and precipitation variability in 19 CMIP2 experiments. J Clim 15:2395-2411

Ranger N (2013) Topic guide: adaptation: decision making under uncertainty. Evidence on Demand. doi:10. 12774/eod tg02.june2013.ranger Accessed 19 Oct 2015

Ranger N, Surminski S (2013) Disaster resilience and post-2015 development goals: the options for economics targets and indicators. Centre for Climate Change Economics and Policy Grantham Research Institute on Climate Change and the Environment. http://www.cccep.ac.uk/Publications/Policy/docs/PP-disasterresilience-post-2015-development-goals-economics.pdf. Accessed 19 Oct 2015

Ribeiro EM, Galizoni FM (2003) Água, população rural e políticas de gestão: o caso do vale do Jequitinhonha, minas gerais. Ambient Soc 2:129-146. doi:10.1590/S1414-753X2003000200008

Sherbinin A (2014) Climate change hotspots mapping: what have we learned? Clim Chang 123:23-37. doi:10. 1007/s10584-013-0900-7

Sillmann J, Kharin VV, Zhang X, Zwiers FW, Bronaugh D (2013) Climate extremes indices in the CMIP5 multimodel ensemble: Part 1. Model evaluation in the present climate. J Geophys Res Atmos. doi:10.1002/ jgrd.50203

Taylor KE, Stouffer RJ, Meehl GA (2012) An overview of CMIP5 and the Experiment Design. Bull Am Meteorol Soc. doi:10.1175/BAMS-D-11-00094.1

Torres RR, Marengo JA (2014) Climate change hotspots over South America: from CMIP3 to CMIP5 multimodel datasets. Theor Appl Climatol 117:579-587. doi:10.1007/s00704-013-1030-x

Torres RR, Lapola DM, Marengo JA, Lombardo MA (2012) Socio-climatic hotspots in Brazil. Clim Chang 115 : 597-609. doi:10.1007/s10584-012-0461-1

UNDP (2014) Human Development Report 2014. Sustaining Human Progress: Reducing Vulnerabilities and Building Resilience. United Nations Development Programme. 1 UN Plaza, New York, NY 10017, USA. 226 p. ISBN 978-92-1-126368-8

Vincent K (2007) Uncertainty in adaptive capacity and the importance of scale. Glob Environ Chang 17:12-24. doi:10.1016/j.gloenvcha.2006.11.009

Walker W, Haasnoot M, Kwakkel J (2013) Adapt or perish: A review of planning approaches for adaptation under deep uncertainty. Sustainability 5:955-979. doi:10.3390/su5030955

World Bank (2010) Development and climate change report. Washington DC, World Bank. doi:10.1596/978-08213-7989-5

Xu Y, Xuejie G, Giorgi F (2009) Regional variability of climate change hot-spots in East Asia. Adv Atmos Sci 26(4):783-792 